\title{
Challenges and Limitations in Additive Manufacturing of Aluminium Alloys for the Aerospace Industry
}

\author{
Sadettin Cem Altiparmak \\ Department of Mechanical Engineering, Imperial College London, \\ London SW7 2AZ, United Kingdom \\ E-mail: s.altiparmak19@imperial.ac.uk
}

\begin{abstract}
Additive manufacturing (AM) processes as the relatively new rapid prototyping technologies for the fabrication of high strength lightweight alloys are one of the most appropriate methods to meet the rising demands in the aerospace industry. In this sense, additively manufactured lightweight aerospace aluminium alloys belong to $2 \mathrm{xxx}$ and $7 \mathrm{xxx}$ series are extensively used in aircraft structures to achieve the decrease in the weight of aircraft structures. AM processes are the appropriate manufacturing techniques to be used in the aerospace industry to fabricate the aerospace components having complex and unique shapes, which is not possible by means of the conventional manufacturing processes. As a result, AM processes have recently an increased attention in academia and industry. However, the use of AM processes in the aerospace industry is restricted resulting from several factors such as the lack of the globally accepted certifications and standards, fabrication speed, additional surface finishing cost, limitation of the production size, achievable precision and micro-fatigue occurrence regarding to the AM of the aerospace components. In this paper, challenges and limitations in the AM of lightweight aerospace aluminium alloys were investigated.
\end{abstract}

Keywords: Additive manufacturing; 3D printing; Aerospace aluminium alloys; Light weighting; Aerospace.

DOI: $10.7176 / \mathrm{JSTR} / 6-05-04$

\section{Introduction}

The "light metals" term has conventionally been referred to aluminium (Al), since the light Al metals are broadly used to decrease the weight of structures and components. The lightness property of metals and alloys is directly associated with the enhancement of material property for various products due to the remarkable decrease in weight in relation to the decrease in density. In this sense, the broadly use of lightweight metals and alloys in the aerospace industrial applications can be link to the decrease in weight and density of the structures and components used. The advantages of decrease in density is considerably essential in engineering design where buckling resistance and stiffness parameters are involved. The advantages of the use of lightweight alloys cannot be restricted as only decrease in density and weight. In addition to this aspect, other mechanical properties of the lightweight alloys have also remarkable technological importance. For instance, Al alloys are characterised by comparatively high corrosion resistance, thermal and electrical conductivity. A number of metallic materials can be additively manufactured these days such as Al, titanium, amorphous Al alloys and titanium aluminide [1].

Thanks to the use of AM processes rather than conventional manufacturing processes, the cradle-to-gate environmental footprint of each aircraft component can be declined. There also, however, various of challenges and limitations in the AM of aerospace Al alloys to be used in the aerospace industry, which include the lack of failure mechanism knowledge for the additively manufactured aerospace components, the globally accepted certifications and standards, extra surface finishing cost, production size limitations, difference between the achievable precision level and tolerance demand, verification and mechanical testing of the aerospace components, fabrication speed and micro-fatigue generation during the service time of the critical aerospace components. In this paper, challenges and limitations in the AM of aerospace $\mathrm{Al}$ alloys were investigated in addition to the AM market trend and micro-fatigue cracking defects taking place in the aerospace components.

\subsection{Additive Manufacturing Processes}

AM processes are expressed as the formalised term for describing of what used to be named as rapid

34 | P a g e

www.iiste.org 
prototyping (RP) and what is recently named as three-dimensional (3D) printing. In terms of product development, the rapid prototyping term is used to classify some technologies in which physical prototypes are fabricated in accordance with an acquisitioned data of a digital model [2]. AM processes are associated with layered manufacturing due to the mechanism of the manufacturing process in which manufacturing parts are fabricated layer-by-layer based on 3D data. In the mechanism of AM processes, previously generated models are fabricated without the necessity of any process planning. Nowadays, AM applications have gradually become widespread in the aerospace industry, particularly in the fabrication of the parts with complex shapes [3].

The group of American Society for Testing and Materials (ASTM) "ASTM F42-Additive Manufacturing" in 2010 formulated the various of standards in order to classify the variety of AM processes used in industry into 7 categories as given in Table 1. These categories are binder jetting, directed energy deposition, material extrusion, material jetting, powder bed fusion, sheet lamination and vat polymerisation [4,5]. The classification of AM processes is illustrated in terms of the physical state of the based raw material as solid or wire extrusion, powder and liquid based AM processes (see Fig. 1).

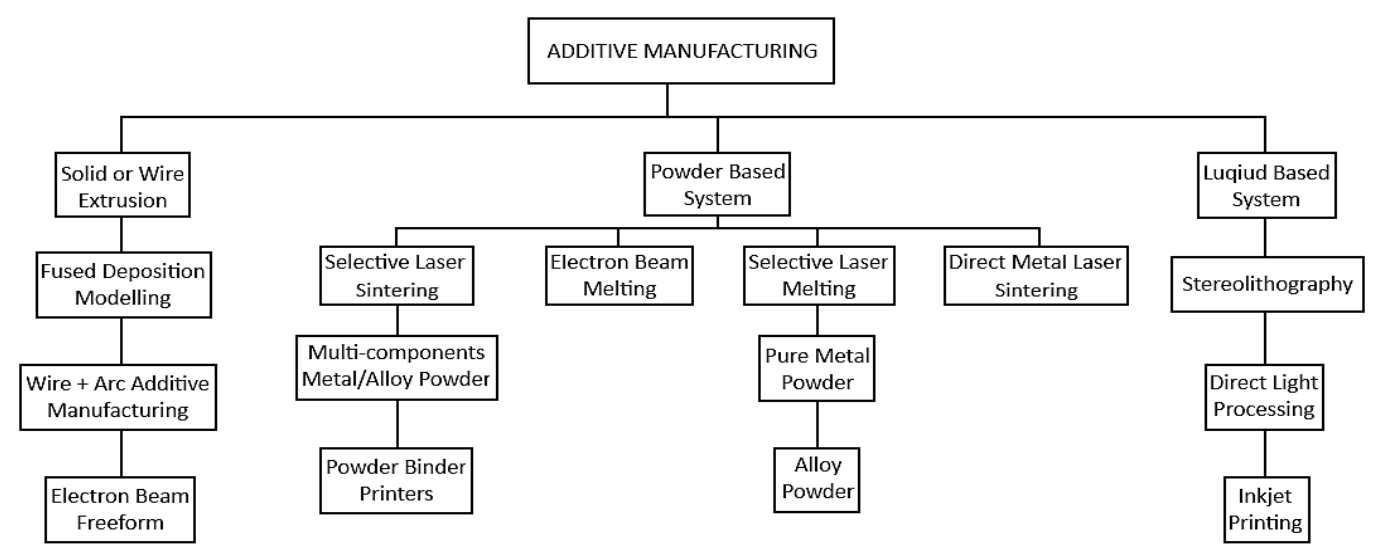

Figure 1. Classification of AM processes [6]

Table 1. Main AM processes [4,7]

\begin{tabular}{|c|c|}
\hline AM Processes & Descriptions \\
\hline $\begin{array}{c}\text { Vat } \\
\text { Polymerization }\end{array}$ & $\begin{array}{l}\text { The parts are printed in a liquid resin photopolymer vat and ultraviolet light is } \\
\text { applied through mirrors to the object }\end{array}$ \\
\hline $\begin{array}{c}\text { Material } \\
\text { Extrusion }\end{array}$ & $\begin{array}{l}\text { Raw materials are extruded by applying melted material via a horizontally } \\
\text { moving heated nozzle as layer-by-layer }\end{array}$ \\
\hline $\begin{array}{l}\text { Powder Bed } \\
\text { Fusion }\end{array}$ & $\begin{array}{c}\text { A laser or electron beam is used in 3D space to melt the ultra-fine material } \\
\text { layers }\end{array}$ \\
\hline $\begin{array}{l}\text { Directed Energy } \\
\text { Deposition }\end{array}$ & $\begin{array}{c}\text { Gun or electron laser is applied to fuse filament feedstock by means of melting } \\
\text { as the filaments are being deposited (materials use; polymers, metals, } \\
\text { ceramics) }\end{array}$ \\
\hline $\begin{array}{c}\text { Sheet } \\
\text { Lamination }\end{array}$ & $\begin{array}{l}\text { A laser is applied to cut materials in the sheet shape. As repeating the } \\
\text { procedure, sheets are joint each other by adhesives }\end{array}$ \\
\hline $\begin{array}{c}\text { Material } \\
\text { Jetting }\end{array}$ & $\begin{array}{c}\text { A head of material jetting print moving } \mathrm{x}, \mathrm{y} \text { and } \mathrm{z} \text {-axes is used. UV light is } \\
\text { implemented in this process to harden the layers }\end{array}$ \\
\hline $\begin{array}{l}\text { Binder } \\
\text { Jetting }\end{array}$ & $\begin{array}{l}\text { As a raw material, both powder and binder are consumed. As spreading the } \\
\text { powder, binder binds the powder via a print head }\end{array}$ \\
\hline
\end{tabular}




\subsection{Merits and Limitations of Additive Manufacturing Processes}

AM processes have several advantages in not only manufacturing but also design. The main merit of the AM processes is flexibility which enhances the industrial efficiency in the manufacturing and design of the products. By applying these processes, elimination of tooling and fixturing help design stage of production, production complexity and development. The AM processes enable manufacturers to make continuously changes at the revised products, which facilitates customisation process with relatively lower cost. Through AM technologies, desired objects can be printed in one time, hence it improves ondemand production and facilitates the building of rapid prototyping. Even parts including hollows are possible to be produced, which leads to decrease in weight of the produced parts that light parts are valuable at some sectors such as aerospace and aviation. Furthermore, joins or welding implementations are not necessary, which enhances the visual integrity and strength of the part being manufactured. Other advantage of the AM processes is that comparatively low energy is consumed at AM implementations with comparatively less material waste rather than traditional manufacturing processes $[8,9]$.

AM processes have a remarkable potential to meet the demands of manufacturers and operation requirements decreasing the design-to-manufacture lead time by eliminating production processes into a single-step process. Contrary to the conventional manufacturing processes, AM processes do not necessitate detailed analyses for the determining of part geometry, selection of type of tool and necessity of additional fixtures to be used. This process elimination in turn leads to fabricating cost-effective products with the help of the minimisation in raw material usage and waste after production. Furthermore, AM processes can conveniently be incorporated changings in design in relatively lesser time by means of various of the available recent software. AM processes enable better level of product quality and remarkable customer satisfaction. AM processes have various of application areas in various fields $[2,10]$.

However, AM processes have several specific limitations. The chief limitation of the AM processes is that the conventional manufacturing techniques are relatively faster at mass production rather than AM processes. The total cost of the AM process can be considerably costly resulting from the expense of the scanning and printing device, software for the reverse engineering and base material. Fabrication of the desired parts in one time decreases the lead time of the parts, however, when any break takes place during the printing process, the fabricated parts become distorted. Moreover, customisation in the postprocessing stage leads to an increase in the total cost of production. Other main demerits of the AM processes are insufficient surface quality of fabricated parts, component size limitation and efforts need to make in the design stage $[11,12]$.

\section{Microstructural Evolution of Aluminium Alloys}

There is a considerable link between the microstructure of Al alloys and the applied AM process and strengthening mechanisms which are work hardening, ageing and annealing of the alloys. Al alloys can be subcategorised in terms of the controllability of the mechanical properties by means of (i) annealing and work hardening, and (ii) precipitation and age hardening [1]. In this context, Al alloys can be subdivided into two groups. One group containing those Al alloys whose mechanical properties are controlled by means of annealing and work-hardening such as commercial-purity Al and Al alloy systems based on the Al-Mg and Al-Mn. The other group involves some of the responsive Al alloys to precipitation and age hardening such as $\mathrm{Al}-\mathrm{Zn}-\mathrm{Mg}-\mathrm{Cu}, \mathrm{Al}-\mathrm{Mg}-\mathrm{Si}$ and $\mathrm{Al}-\mathrm{Cu}-\mathrm{Mg}$ [1]. The contributing techniques by which control the microstructure and mechanical properties of Al alloys can be controlled or adjusted are as following. The conventional techniques to improve the mechanical properties of Al alloys contain the plastic strain use for nanostructuring [13], alloying by means of appropriate alloying elements e.g. $\mathrm{Si}, \mathrm{Cu}, \mathrm{Mg}$ and $\mathrm{Zr}$ [14] and controlled dispersoids formation in the Al matrix [15]. In terms of hardening of $\mathrm{Al}$ alloys, two classification have been suggested in the literature: (i) wrought $\mathrm{Al}$ alloys, (ii) cast $\mathrm{Al}$ alloys. The main point for this classification is the difference in influential mechanisms to make Al alloys hardened between the wrought and cast $\mathrm{Al}$ alloys.

Several Al alloys are capable to respond to the prespecified thermal treatments by changing of their phase solubilities and successive formation of the in situ fine dispersoids. In this context, these responsive Al alloys to prespecified thermal treatments are referred in the literature as heat treatable Al alloys which can be strengthened through the range of heat treatments containing age hardening, quenching and solution heat treatments [16]. In other words, the enhancement in the mechanical properties is achieved through precipitation processes in which some alloying elements need to make in situ precipitates possible following to ageing. On the other hand, several cast or wrought Al alloys can be hardened after a controlled heat treatment approach. For the non-heat treatable Al alloys, work-hardening is beneficial approach in order to make non-heat treatable Al alloys strengthened [17].

36 | P a g e

www.iiste.org 
Non-heat treatable Al alloys are able to resist the Al-based grain network generation comprising cold work induced dislocations. Different form the Al alloys which are non-heat treatable, the heat treatable Al alloys consist of the microstructures having (i) Al grains in solution with the concentration of high amount of alloying elements, relatively coarse dispersoids generating during the solidification or homogenisation, (iii) fine in-situ particles taking place in the matrix grains [18]. Therefore, the most suitable strengthening mechanisms by which the microstructures of $\mathrm{Al}$ alloys can be controlled for the non-heat treatable alloys are solid solution and dislocation strengthening, whereas those for the heat treatable Al alloys are the precipitation hardening and grain refinement [19].

Grain size is also one of the chief metal features which considerably affects the microstructural characteristics of $\mathrm{Al}$ alloys. Materials with finer grain sizes are relatively harder and stronger compared to the those with coarse grain sizes due to the higher number of the metal grain boundaries which hinders the dislocation motion. In this context, nanostructuring and the grain refinement can lead to remarkable enhancement in the mechanical strength of $\mathrm{Al}$ alloys [20]. This general relationship between the average grain size $(d)$ and the yield stress $(\sigma)$ based on the dislocation pile-ups concept at the grain boundaries was fully proposed by Hall-Petch relation in equation below. However, the Hall-Petch equation as shown in Equation 1 can possibly lose the validity for the smaller grain size obtained less than $25 \mathrm{~mm}$ due to the inverse Hall-Petch effect and yield plateau [21].

$$
\sigma=\sigma_{0}+k d^{-1 / 2}
$$

where $k$ and $\sigma_{0}$ represent the strengthening coefficient and starting friction opposing the dislocation movement of materials respectively

Throughout the deformation of Al alloys, dislocation content tends to increase in the case of faster multiplication and dislocation generation occurrence than the possible annihilation taken place by dynamic recovery. In this procedure, grain walls, cells and tangles are formed, while the internal structures and grain shapes are modified at the same time. In consequence of all these factors, the distance of mean free slip declines and strength level enhances. If slip occurs in the individual grains and the grains elongate, there can possibly be a remarkable increment in the total grain boundary area. Regarding to multiphase $\mathrm{Al}$ alloys comprising finer dispersoids and coarse size intermetallic particles, deformation takes place more inhomogeneous. The density of the deformed zones can be much higher within the metal matrix composites and comparatively finer dispersoids throughout the thermomechanical Al alloy processing can assist to pin grain boundaries [1].

The main microstructural features which affect and adjust the mechanical properties of Al alloys can be briefly summarised as following [1]:

- $\quad$ Fine precipitates up to $1 \mu \mathrm{m}$ and form throughout the age hardening. The fine precipitates have a great deal of impact on the strengthening of Al alloys able to respond such treatments.

- Grain shape and size of Al alloy is by far the most important feature which varies wrought products e.g. extrusions, forgings and sheets form plate. Al throughout the hot deformation recovers itself continuously by generating a subgrain network. The characteristic feature is generally associated with the relatively high stacking-fault energy of Al. As a result, elongated grain structure can be possibly retained.

- Crystallographic textures which generates due to annealing and working dominantly in rolled products. The crystallographic textures have a notable impact on formability of Al alloys resulting in anisotropic mechanical behaviours.

- Coarse intermetallic compounds, also called as constituent particles, which can be generated interdendritically as a result of eutectic decomposition throughout the ingot solidification. Constituent particles do not serve any beneficial function for high strength wrought Al alloys.

- Dispersoids or smaller submicron particles are formed throughout the ingot homogenisation because of the solid-state precipitation of compounds. When the smaller submicron particles formed, these particles have capability to resist either coarsening or dissolution. The compounds serve to the grain growth throughout the processing and retard crystallisation.

\subsection{Studies on suitability for Additive Manufacturing}

In the literature, numerous approaches have been developed for the implementations of AM processes, some of which are given in Table 2. Briefly, the developed procedure model of [22] was planned on the purpose of design and implementations of AM processes focusing on until any decision was taken by company or manufacturers. However, the study does not comprise the application-oriented tools 37 | $P$ a g e 
regarding to the companies interested. The other conceptual models which are [23] and [24] principally focused on the AM process implementations taken place after the final decision about using the AM processes. Nevertheless, the evaluated process by the final decision was not taken into consideration.

[25] presented a suitability analysis which is user-friendly and well-structured model in order to evaluate the product suitability for the current AM processes. The created suitability analysis taken from the literature is illustrated (see Fig. 2) comprising in total six essential parameters including economic and technical analyses in addition to the selection of the most appropriate AM process and materials to be used.

Table 1. Main AM processes [4,7]

References Descriptions

$[22]$

Decision-making process which considers both the implementations of AM and investment

[23]

Developed conceptional framework for AM implementations covers both the external parameters and internal parameters e.g. supply chains, strategic parameters The framework of AM processes regarding to mass customisation taking into technological, external, operational and strategic parameters account

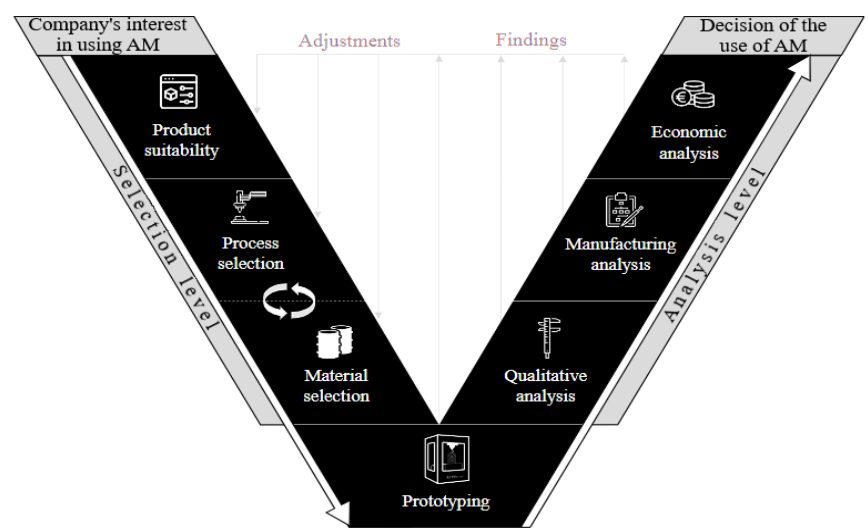

Figure 2. Example of the suitability analysis for AM processes [25]

\section{Additive Manufacturing of Aerospace Aluminium Alloys}

AM processes have four the main application areas in aerospace industry as; the manufacturing of tooling, manufacturing of components, repairing of tooling and repairing of components. Some of the aerospace applications in which AM processes have potential to be used are rib-web structural components, turbine engine cases, engine blades and engine vanes. A great majority of the aircraft substructures is mostly included rib-web components e.g. ribs, longerons and bulkheads. The rib-web components are characterised a web reinforced planar perpendicular to ribs in order to capably carry the existed aircraft loads. The rib-web components are basically machined resulting in components with 10:1 or higher buy-to-fly ratio. Turbine engine cases are the essential structural components to form the outer surface of turbine engines. The turbine engine cases are included thick sections having a small number of asymmetric protuberances. In this context, the buy-to-fly ratio of turbine engine cases can be linked to the height of protuberances and be in some cases higher compared to those for rib-web components. Engine vanes and blades basically include sections with complex airfoil-shape containing internal cooling passages. Even though engine vanes and blades have relatively low buy-to-fly ratio, these components may possibly be costly to procure in conjunction with the expenses caused by the experiencing of damage and wear throughout the service life. For these aerospace components, nearly net shape AM processes enable various potential benefits such as reduce in raw material use due to decreased buy-to-fly ratio, machining operation, machining and tooling expenses, repair cost and volume of raw material stock [26].

The distinctive feature of the fused-based AM processes mostly used for fabrication of the aerospace components is the rapid solidification and melting cycles of the fused-based AM processes which make high cooling rate possible enabling the satisfactorily fine grains [27]. Additionally, the flexibility of 
fusion-based AM processes allows the various of controllable microstructural features e.g. topography, texture and grain structure by means of process parameter manipulation throughout the fabrication stage, which is critically essential to fabricate high performance aerospace components to operate in challenging extreme environments such as prolonged lifespans, harsh weather and elevated temperature levels [28].

In comparison with conventional manufacturing processes e.g. casting, machining, thermoforming, finishing and moulding, AM processes enable three the main advantageous promising features related to the aerospace industry and components to be used in aviation applications. To begin with, designing aerospace components having novel geometries improves the engineering performance of components, which is not possible by using conventional manufacturing processes [29]. AM also have capacity to decline the cradle-to-gate environmental footprints, which is a full life cycle assessment between the extraction of source and factory gate prior to the transportation to customers [31], of the aircraft components being used in aerospace industry. In this context, the decline in the cradle-to-gate environmental footprints can be obtained by eliminating the material scrap dies and tools by using AM processes rather than conventional manufacturing processes [31]. Lastly, AM processes enable various benefits in terms of the product application of the components e.g. AM processes were adopted by aircraft industry to obtain reduced aircraft mass including seat buckles, brackets etc. leading to remarkable efficiency of aircraft fuel [32]. The typical total weight distribution of an aircraft is given (see Fig. 3).

Aviation is the largest sector consuming the transport fuels. In this regard, aircraft use having comparatively lighter weight can be mentioned as a result of the global critical strategy in order to decrease the greenhouse gas emission and societal energy usage. The global consuming of aircraft fuel is anticipated to triple by the year of 2050 due to the gradually increasing globalisation and tourism [32]. Recently the cost of materials being used for AM processes are comparatively higher rather than materials in conventional manufacturing. However, AM processes allow manufacturers to the lower raw material required for the final mass of components range, also called buy-to-fly ratio, and recyclability, which considerably declines the total cost manufacturing [34]. The buy-to-fly ratio is between 10:1 and 25:1 for Al aircraft components produced by conventional manufacturing processes, which can be even 40:1 depending on the complexity of the aerospace components. These buy-to-fly ratio lead to considerable amount of increase in the material scrap throughout the cradle-to-gate manufacturing resulting the relatively higher manufacturing cost and footprints of environmental gas emission [35]. Regarding to the buy-to-fly ratio, AM processes allow manufacturers to produce almost net shape components having the reduced buy-to-fly ratio, even close to 1:1. The principal advantage of AM processes over conventional manufacturing processes is the enabling nearly net-shaped products with 1:1 buy-to-fly ratio and approximately $10-20 \%$ scrap rates, which results in a remarkable decline in both the use of input material and necessity of the post-processing machining [36].
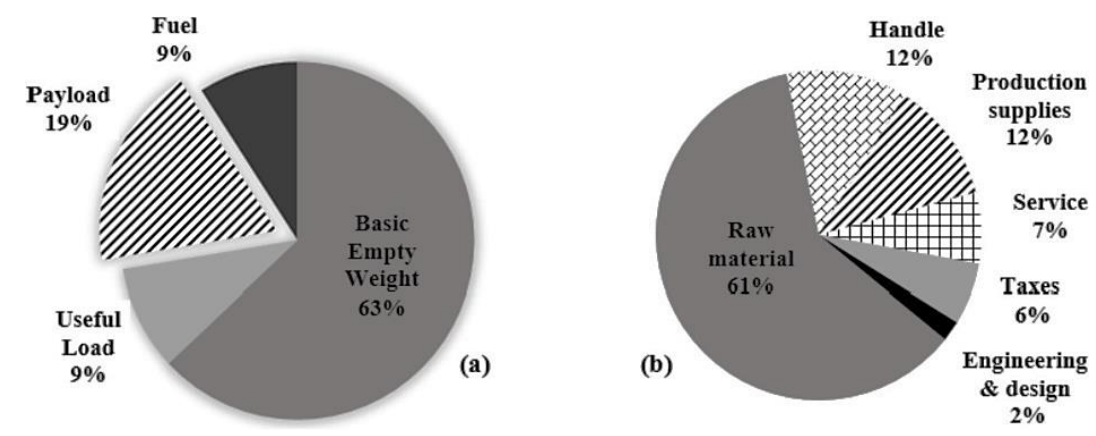

Figure 3. Distribution of the (a) Weight used; (b) Cost production in aircrafts [35]

\subsection{Aerospace Market for Additive Manufacturing of Aluminum Alloys}

AM processes in the aerospace industry is recently experiencing a progressive upward trend of fabrication of numerous aircraft components as $16.6 \%$ and $18.2 \%$ of the global industry market share in the year of 2016 and 2017. The market share percentage is also projected to reach at $20.24 \%$ by 2023 [37]. AM processes are being established recently as an effective fabrication technology which leads to remarkable revenue to the aerospace industry throughout the repair operations and supply chains. The total revenue increment of AM industry is generally originated from the aerospace industry (see Fig. 4)

39 | P a g e

www.iiste.org 
in which the dramatic increase in the AM revenue can be seen. The aerospace sector as the fastest growing sector of 2016 experienced the $1.6 \%$ growth rate, following the $1.0 \%$ growth rate in the motor vehicle sector. The total revenue of AM processes in 2016 is forecasted as $\$ 2.7$ billion having the $12.9 \%$ growth rate compared to the previous year [34]. According to Wohlers Report 2018, 1,768 metal AM systems were commercially sold in the year of 2017 compared to the that of in 2016 which was only 983 metal AM systems. Moreover, the growth rate of AM processes in terms of revenue was determined as $21 \%$ exceeding $\$ 7.3$ billion. In the year of $2019,18.2 \%$ of the total revenue of AM industry is originated from the aerospace industry [38]. The total revenue of AM processes is estimated to surpass $\$ 100$ billion in the following two decades particularly due to the revenue increment in the aerospace industry [34].

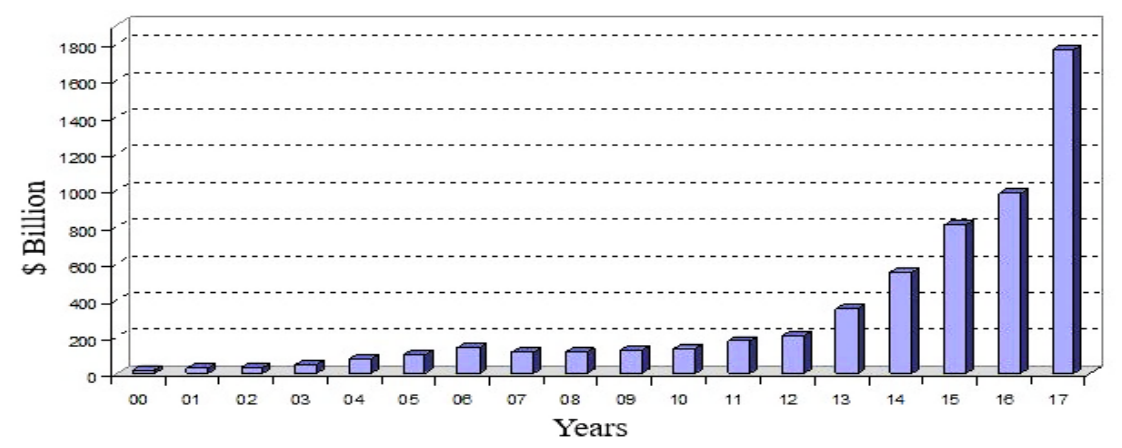

Figure 4. Dramatic increment in sales of metal AM systems in industry between 2000-2017 [38]

The market for additively manufactured $\mathrm{Al}$ alloy components in aerospace industry can be classified into two categories as metallic and non-metallic components in terms of the experienced conditions as critical and noncritical aircraft components respectively. Non-metallic components are in use since the middle of $90 \mathrm{~s}$ by Bell helicopter and Boeing. As a milestone of the use area of additively manufactured components in the aerospace industry, Boeing fabricated almost 200 unique components to be used in various of aircrafts some of the aircrafts in which Al was used dominantly are given (see Fig. 5). Large number of non-metallic additively manufactured components which were more than 20,000 in total were installed to be used in airplanes [39]. 20\% weight saving after using the additively fabricated components in the aircraft structures led to $10-12 \%$ fuel efficiency in Boeing 787 aircrafts [40]. Boeing also fabricated numerous alloy components to be used in 787 Dreamliner aircraft aiming to the additively fabricated 1000 components to save up to $\$ 3$ million for each of the airplane [41].

AM processes have a considerable market volume in the aerospace industry (see Fig. 6) a result of being widely used in several current aerospace applications. In this context, Airbus can be possibly mentioned as the biggest player in the AM market of Al alloys. Airbus company completed the first installation of the additively fabricated metal brackets as a part of A350 XWB aircraft pylon and bleed pipes for Airbus A320neo [43]. Recently, NASA and SpaceX started an exploration for the use of additively fabricated igniters, combustion chambers and injectors for their rocket engines. Other dominant players in the market are Lockheed Martin, Northrop Grumman and Honeywell Aerospace [37].
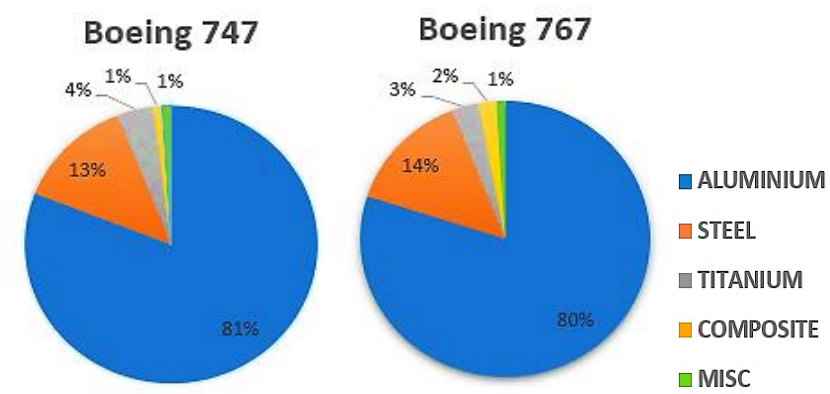

Figure 5. Material distribution in some of the Boeing aircrafts [42] 


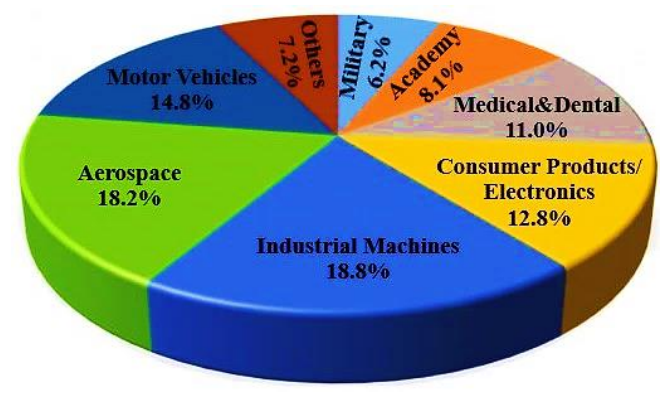

Figure 6. AM market share in industry for the year of 2017 [44]

\section{Barriers and Challenges in Additive Manufacturing for Aerospace Industry}

Even though AM is recently experiencing a progressive adoption in aerospace industry, AM can be still considered as a developing relatively new technology. Because of the lack of the associated globally accepted standards and certification for additively manufactured aerospace components, manufacturers have aimed to develop new standards to meet the AM capabilities [45,46]. Even though several standards related to metal AM have been developed, however, a few associated standards have been established for AM in aerospace industry e.g. SAE AS9100 and MSFC-STD-3716. A remarkable effort still needs to be made to entirely integrate the AM standards to meet the requirements of the recent aerospace industrial applications, which is pioneered by the National Aeronautics and Space Administration [47].

There are, however, some existing special issues related to the current AM applications in aerospace industry. For instance, surface finishing operation is generally a requirement for additively fabricated $\mathrm{Al}$ alloy parts to be used in aerospace applications. Aerospace components having relatively complex shapes require several unconventional methods such as chemical etching generally to remove oxide scaling, shot peening and vibrahoning [3]. This necessity in return restricts the complexity level of the optimised parts because of the consideration of surface finishing feasibility and need increasing the manufacturing cost [48]. Moreover, the surface finishing operations leads to longer lead time and declined buy-to-fly ratio for the aerospace components. Aerospace industry should characteristically fulfil the high safety and quality requirements. That is why all the aircraft components are obligated to be qualified and then certified. These mentioned factors motivate the aerospace industry to create public standards [49]. However, ongoing researches to build standards are naturally lack of consensus and open ended [48].

Despite the various of advantageous applications of AM processes to produce structural aerospace components such as engine mount and turbine blades, the utilisation of mission-critical aircraft parts is nowadays challenging. The main issue is derived from the deficiency of technological standards because of the fast growth of AM processes in recent decades. Establishing the standards is basically expected to ensure the reliability and consistency of the additively fabricated commercial aerospace components and reduce the probable failure of the critical aircraft components in use. The standardised certifications functionally comprise the quality of the additively as-fabricated aerospace components and the repeatability of the individual production processes [50]. The principal complication regarding the certification guidelines can be mentioned as the lack of the knowledge with regard to the failure mechanisms of additively fabricated aircraft components, particularly the fatigue failure of the components which is critically essential in aerospace industry owing to the cyclic nature of the load applied in the aerospace components. On the other hand, the design flexibility of AM processes facilitates the topology optimisation and hybrid additive/subtractive manufacturing approaches improving the quality of the AM-fabricated aerospace components and structures [51].

AM processes were used so far in some of the new released aircrafts such as Boeing 777. In this aircraft, lightweight $\mathrm{Al}$ alloys (7055-T77, 2024-T3, 7150-T77) were used to achieve the fuel efficiency and decline aircraft weight up to $70 \%$ of material distribution (see Fig. 7) [52]. However, AM processes have not been extensively used in Boeing 777 and other aircrafts. The reasons behind this can be stated as relatively slow fabrication speed and limitation in the component size for large aerospace components. Moreover, most of the aerospace components are demanded to have high precision resulting from the safety criterion of the aerospace components. In this context, the achievable precision of additively manufactured components is generally $30-40 \mu \mathrm{m}$, although the tolerance demand of the aerospace companies is mostly less than $10 \mu \mathrm{m}[53]$. 
Another noteworthy challenge for the AM of components being used in the aerospace industry is the mechanical testing and verification of the additively as-fabricated components. Non-destructive testing (NDT) is commonly used in order to investigate the defects of AM-fabricated aerospace components e.g. gas inclusion and cracks. However, the investigation of defects becomes considerably problematic owing to the simultaneously occurring thermal, chemical and physical phenomena throughout the AM processing, which restricts the applications of AM in aerospace industry in global scale. Components produced by means of AM processes to be used in mission critical structures are obliged to be tested and evaluated more rather than components in the use of non-mission critical components. These tests are classically consisted of fracture toughness measurement, proof testing, and non-destructive evaluations as well as safe-life testing which increase the total expense for manufacturers [54]. During the AM of aerospace components in large quantities, the deficiency of the production constrains can possibly deteriorate the quality and geometric accuracy of the as-built components, which can be associated with critical issues such as internal cracks, microstructural aberrations and porosity [55].

\section{BOEING 777}

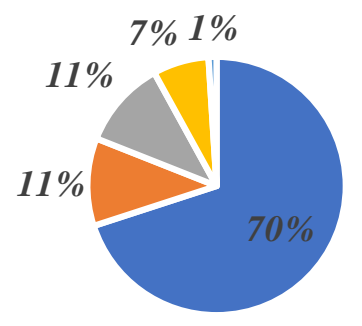

- Aluminium

- Steel

- Titanium

Figure 7. Material distribution of Boeing 777 aircraft [52]

As mentioned earlier, fatigue life is critically essential for the aerospace components produced through AM processes due to the cycling loadings generally at elevated temperature levels for the service time period. Even though some of the static mechanical properties of AM-fabricated aerospace components e.g. hardness, ultimate tensile and yield strength have been assessed, dynamic properties i.e. creep, and fatigue of the aerospace components have been inadequately reported in the literature. Insufficient amount of the studies in the literature reporting the fatigue tests can be linked to the lack of the unified aerospace-based test standards and nomenclatures. The recent available fatigue testing results for AMfabricated aerospace components have pointed out that porosity, defects, surface roughness and fatigue cracking have capacity to promote the wide scattering data regarding to the regimes of both high cycle fatigue (HCF) and low cycle fatigue (LCF) [56].

\subsection{Micro-Fatigue Cracking Defect in Aluminum Aerospace Components}

Aircraft wings are exposed to bending and torsion during the flights in addition to the wing loads deriving from take-off and landing. The upper wing surface is predominantly subjected to tension throughout the taxiing and compression due to the emerging upwards bending moment throughout the flights. The $2 \mathrm{xxx}$ Al alloy series containing magnesium (Mg) element in their chemical composition (2024 and 2014 are the most common examples) have comparatively higher strength causing to superior damage tolerance, $\mathrm{Al}_{2} \mathrm{CuMg}$ and $\mathrm{Al}_{2} \mathrm{Cu}$ phase precipitation and sufficiently good level of the fatigue crack growth resistance in comparison to the other $\mathrm{Al}$ alloy series. In this context, the resistance of fatigue crack initiation and corrosion, growth rate of fatigue crack, strength, stiffness and fracture toughness properties which restricts the design parameters of the $2 \mathrm{xxx}$ and $7 \mathrm{xxx} \mathrm{Al}$ alloy series are critically essential [57].

One of the principal limitations of aerospace $\mathrm{Al}$ alloys is the relatively poor level of fatigue strength compared to steels. For instance, the typical fatigue resistance of 7xxx series of high strength Al alloys in the high-cycle regime which represents more than the cycles number of 5 million is only ranging between 140-160 MPa [57]. The main reason of the applying surface treatments to improve fatigue strength by means of enduring the micro fatigue crack initiation and growth is that fatigue microcracks predominantly initiate on the surface of aerospace Al components. In this context, high strength aerospace $\mathrm{Al}$ alloys are commonly subjected to some surface treatments including hard coating and shot peening. In this sense, some of the appropriate protection treatments including anodising, coating and painting are widely applied on the surfaces of high strength aerospace Al alloys to obtain an improvement in these $\mathrm{Al}$ alloys in terms of fatigue, wear and cracking resistance. Recently, both aircraft designers and

42 | P a g e

www.iiste.org 
material producers are aiming to increase the fatigue and corrosion resistance of aircraft components by reducing weight to be used in industrial aerospace applications. It is anticipated that aircraft structures being used in near future will possibly have extended fatigue and service life. The manufacturers are also endeavouring to decrease the number of aircraft parts in aircrafts by producing thicker and larger plates having the equivalent fracture and fatigue characteristics to those of thin plates [59].

$2 \mathrm{xxx}$ series of $\mathrm{Al}-\mathrm{Cu}$ alloys are normally preferred for particularly fatigue critical applications thanks to their relatively higher damage tolerance and $2 \mathrm{xxx}$ series of $\mathrm{Al}$ alloys containing magnesium element in their composition have comparatively higher fatigue crack growth resistance because of the precipitation of $\mathrm{Al}_{2} \mathrm{CuMg}$ and $\mathrm{Al}_{2} \mathrm{Cu}$ phases. In this sense, the resistance of fatigue cracking initiation and fatigue growth rate can be mentioned as the critical parameters which limit the design of aircraft and aircraft components [57]. 7xxx Al alloys are the most appropriate option for the fabrication of stringers, upper wing skins and stabilisers. Regarding the structural design of upper wing components, both fatigue resistance and compressive strength are the critical design parameters. Moreover, structural design of the horizontal/vertical stabilisers is critically essential for the airplane wings in addition to those for airplane tails due to the exposed compressional loading derived from bending. 7075-T6 Al alloys are commonly selected to be used in aircraft structures with the help of various of mechanical characteristics of the alloy e.g. high machinability, low cost and comparatively high strength-to-weight ratio. However, AA7075 is remarkably susceptible to the occurrence of corrosion because of the chemical composition of the alloy and corrosive exposed working environment including rain, humidity, saltwater and extreme temperature levels [60].

Fatigue as one of the most critical mechanical properties of structural aerospace components should be critically considered particularly when the coated components subjected to the fluctuating loads. Considering the alleviant effects of protective surface coatings on fatigue crack propagation, protective coatings are highly relevant to $\mathrm{Al}$ aerospace components may necessitate to be protected in extreme operating conditions from microcrack initiation caused by fatigue existence [61]. [61] investigated the fatigue behaviour and fatigue crack propagation of 7075-T6 aerospace Al alloy coated with $3 \mu \mathrm{m}$ thickness titanium nitride (TiN) by means of physical vapour deposition process. In order to detect the distinctive macro features and observe the fatigue crack propagation of the surface of fractured 7075-T6 Al alloy, initial fractography examination was employed by means of an optical microscopy. The formation of initial fatigue cracks generated from a side of the emerging fracture surface then started to be progressed until the final ductile failure after 781,000 cycles. The fatigue fractured surfaces of TiN coated and TiN coated+post heat treated $7075 \mathrm{Al}$ alloy specimens were investigated to detect the locations of the micro fatigue crack initiation and propagation on the fracture surfaces. The propagation direction of micro fatigue cracks is highlighted on the microscope view. At the end of the study, the generation of the micro fatigue cracks initiation was determined under the TiN protective coating at the outer surface of 7075-T6 Al substrate.

\section{Conclusion}

This review paper leads to these conclusions as following:

- AM processes are one of the most appropriate techniques to decrease the cradle-to-gate environmental footprint, weight, production cost, and improve the quality and structure integrity of the lightweight $\mathrm{Al}$ aircraft components

- There is a considerable effort made by manufacturers and aerospace companies in the aerospace industry to enlarge the AM processes of the lightweight aerospace Al alloys to be used in aircraft components and structures

- The use of AM processes in the aerospace industry is limited due to several reasons such as lack of the global certifications, standards, and failure mechanism knowledge, limitation of the production size, additional surface finishing cost, reachable precision, fabrication speed and micro-fatigue occurrence in the critical aerospace components

- As a result of the lack of globally established associated certifications and standards for the additively manufactured aerospace components, the current AM usage in the aerospace industry has been limited for the non-mission critical applications. To address this limitation, manufacturers are currently making a progressive effort to develop new standards in order to meet the potential capabilities on the AM processes 


\section{References}

[1] Polmear, I.; StJohn, D.; Nie, J.F.; Qian, M. Light alloys: metallurgy of the light metals. 5th ed. Oxford: Butterworth-Heinemann. 2017.

[2] Gibson, I; Rosen, D.; Stucker, B. Additive Manufacturing Technologies: 3D Printing, Rapid Prototyping, and Direct Digital Manufacturing. 2nd ed. New York: Springer. 2015.

[3] Shapiro, A.A.; Borgonia, J.P.; Chen, Q.N.; Dillon, R.P.; McEnerney, B.; Polit-Casillas, R.; Soloway, L. Additive manufacturing for aerospace flight applications. Journal of Spacecraft and Rockets, 2016, 952-959.

[4] ASTM International. Standard Terminology for Additive Manufacturing Technologies. 2015. [Online] Available at: http://web.mit. edu/2.810/ www/files/ readings/ AdditiveManufacturing Terminology.pdf [Accessed 1312 2019].

[5] Anon. The 7 Categories of Additive Manufacturing. 2019. [Online] Available at: https://www.lboro. ac.uk/ research/amrg/about/the7categoriesofadditivemanufacturing/ [Accessed 1312 2019].

[6] Rajaguru, K.; Karthikeyan, T.; Vijayan, V. Additive manufacturing - State of art. Materials Today: Proceedings, Issue https://doi.org/ 10.1016/j.matpr.2019.06.728, 2019, pp. 1-6.

[7] Haleem, A.; Javaid, M. 3D printed medical parts with different materials using additive manufacturing. Clinical Epidemiology and Global Health, https://doi.org/10.1016/j.cegh.2019.08.002, pp. ISSN 2213-3984. 2019.

[8] Kim, H.; Lin, Y.; Tseng, B. A review on quality control in additive manufacturing. Rapid Prototype Journal. 2018, 24(3), pp. 645-669.

[9] Javaid, M.; Haleem, A. Using additive manufacturing applications for design and development of food and agricultural equipments. International Journal of Materials and Product Technology. 2019, 58(2/3), pp. 225-238.

[10] Grigoriev, A.; Polozov, I.; Sufiiarov, V.; Popovich, A. In-situ synthesis of Ti2AlNb-based intermetallic alloy by selective laser melting. Journal of Alloys and Compounds. 2017, 704, pp. 434-442.

[11] Bastola, A.K.; Paudel, M.; Li, L. Development of hybrid magnetorheological elastomers by 3D printing. Polymer. 2012, 18(6), pp. 443-450.

[12] Sabu, S.S. SlideShare. 2019. [Online] Available at: https://www.slideshare.net /StephinAbraham Sabu /additive-manufacturing-ppt [Accessed 710 2019].

[13] Taherian, M.M.; Yousefpour, M.; Borhani, E. The effect of ARB process on corrosion behavior of nanostructured aluminum alloys in $\mathrm{Na} 2 \mathrm{HPO} 4 \cdot 12 \mathrm{H} 2 \mathrm{O}$ and $\mathrm{Zn}(\mathrm{NO} 3) 2 \cdot 6 \mathrm{H} 2 \mathrm{O}$ PCMs. Engineering Failure Analysis. 2020, 107, pp. 104222.

[14] Torrescano-Alvarez, J.M.; Curioni, M.; Habazaki, H.; Hashimoto, T.; Skeldon, P.; Zhou, X. Incorporation of alloying elements into porous anodic films on aluminium alloys: The role of cell diameter. Electrochimica Acta. 2019, 296, pp. 783-789.

[15] Yan, Z.; Lin, Y. On the widths of stacking faults formed by dissociation of different types of full dislocations in a nanostructured Al alloy. Materials Science and Engineering: A. 2020, 770, pp. 138532.

[16] Shan, D.; Zhen, L. Aging behavior and microstructure evolution in the processing of aluminum alloys. In: Microstructure Evolution in Metal Forming Processes. Harbin Institute of Technology, China: Woodhead Publishing. 2012, pp. 267-297.

44 | $\mathrm{P}$ a g e

www.iiste.org 
[17]Lumley, R. Fundamentals of aluminium metallurgy: production, processing and applications. Philadelphia, USA: Elsevier. 2010.

[18] Song, Y.; Xiong, B.Q.; Zhang, Y.A.; Li, X.W.; Li, Z.H.; Huang, S.H.; Yan, H.W.; Liu, H.W. Effect of two-step aging process on microstructure and fracture toughness of 7085 aluminum alloy. Materials Science Forum. 2016, 852, pp. 149-155.

[19] Azarniya, A.; Taheri, A.K.; Taheri, K.K. Recent advances in ageing of 7xxx series aluminum alloys: A physical metallurgy perspective. Journal of Alloys and Compounds. 2019, 781, pp. 945-983.

[20] Ishikawa, T. Understanding and controlling microstructural evolution in metal forming: an overview. In: J. B. D. \&. P. M. Lin, ed. Microstructure Evolution in Metal Forming Processes. Nagoya University, Japan: Woodhead Publishing Series in Metals and Surface Engineering. 2012, pp. 3-16.

[21] Petch, N.J. The cleavage strength of polycrystals. Journal of the Iron and Steel Institute. 1953, 174, pp. 25-28.

[22]Feldmann, C.; Pumpe, A. 3D-Druck-Verfahrensauswahl und Wirtschaftlichkeit. In Entscheidungsunterstützung für Unternehmen. Springer Gabler Wiesbaden. 2016.

[23] Mellor, S.; Hao, L.; Zhang, D. Additive manufacturing: A framework for implementation. International journal of production economics. 2014, 149, pp. 194-201.

[24]Deradjat, D.; Minshall, T. Implementation of rapid manufacturing for mass customisation. Journal of Manufacturing Technology Management. 2017.

[25]Ilg, J.; Oehler, A.; Lucke, D. A Suitability Analysis Method for Additive Manufacturing Technologies in Small and Medium-Sized Companies. Procedia CIRP. 2019, 81, pp. 612617.

[26] Kobryn, P.A.; Ontko, N.R., Perkins, L.P.; Tiley, J.S. Additive manufacturing of aerospace alloys for aircraft structures. Neuilly-sur-Seine, France, Air Force Research Lab WrightPatterson AFB OH Materials and Manufacturing Directorate. 2006.

[27] Oliveira, J.P.; Santos, T.G.; Miranda, R.M. Revisiting fundamental welding concepts to improve additive manufacturing: From theory to practice. Progress in Materials Science. 2020, 107, pp. 100590.

[28] DebRoy, T.; Mukherjee, T.; Milewski, J.O.; Elmer, J.W.; Ribic, B.; Blecher, J.J.; Zhang, W. Scientific, technological and economic issues in metal printing and their solutions. Nature materials. 2019, 18, pp. 1026-1032.

[29] Horn, T.J.; Harrysson, O.L. Overview of current additive manufacturing technologies and selected applications. Science progress. 2012, 95(3), pp. 255-282.

[30]Cao, C. Sustainability and life assessment of high strength natural fibre composites in construction. In: M. F. a. F. Fu, ed. Advanced High Strength Natural Fibre Composites in Construction. s.1.:Woodhead Publishing. 2017, pp. 529-544.

[31] Serres, N.; Tidu, D.; Sankare, S; Hlawka, F. Environmental comparison of MESO-CLAD® process and conventional machining implementing life cycle assessment. Journal of Cleaner Production. 2011, 19(9-10), pp. 1117-1124.

[32] Carrington, D. Jet Engine Makers Get Lift from 3-D Printing Technology. 2013. [Online] Available at: http://edition.cnn. com/travel /article/ leap-engine- 3-d-printing/ index.html [Accessed 17 January 2020]. 
[33] Singh, V.; Sharma, S.K. Fuel consumption optimization in air transport: a review, classification, critique, simple meta-analysis, and future research implications. European Transport Research Review. 2015, 7(2), pp. 1-18.

[34] Kumar, L.J.; Nair, C.G.K. Current trends of additive manufacturing in the aerospace industry. In: D. I. Wimpenny, P. M. Pandey \& L. J. Kumar, eds. Advances in 3D Printing \& Additive Manufacturing Technologies. Kumar, L.J.; Nair, C.G.K. Current trends of additive manufacturing in the aerospace industry. In Advances in 3D Printing \& Additive Manufacturing Technologies; Springer: Singapore, 2017; pp. 39- ed. Singapore: Springer. 2017, pp. 39-54.

[35] Torres-Carrillo, S.; Siller, H.R.; Vila, C.; López, C.; Rodríguez, C.A. Environmental analysis of selective laser melting in the manufacturing of aeronautical turbine blades. Journal of Cleaner Production. 2020, 246, pp. 119068.

[36] Rawal, S. Materials and structures technology insertion into spacecraft systems: Successes and challenges. Acta Astronautica. 2018, 146, pp. 151-160.

[37] Najmon, J.C.; Raeisi, S.; Tovar, A. Review of additive manufacturing technologies and applications in the aerospace industry. In: F. F. a. R. Boyer, ed. Additive Manufacturing for the Aerospace Industry. s.1.:Elsevier. 2019, pp. 7-31.

[38] Campbell, I.; Diegel, O.; Kowen, J.; Wohlers, T. Wohlers report 2018: 3D printing and additive manufacturing state of the industry: annual worldwide progress report. Wohlers Associates. 2018.

[39] Liu, R.; Wang, Z.; Sparks, T.; Liou, F.; Newkirk, J. Aerospace applications of laser additive manufacturing. In: M. Brandt, ed. Laser Additive Manufacturing - Materials, Design, Technologies, and Applications. amsterdam, the netherlands: Woodhead Publishing. 2017, pp. 351-371.

[40] Marino, M.; Sabatini, R. Advanced lightweight aircraft design configurations for green operations. In Practical Responses to Climate Change Conference 2014. Engineers Australia. 2014, pp. 207.

[41] Mearian, L. Boeing Turns to 3D-Printed Parts to Save Millions on its 787 Dreamliner. April 11, $2017 . \quad$ Available from: https://www.computerworld.com/article/3188899/3dprinting/boeing-turns-to-3d-printedparts-to-save-millions-on-its-787-dreamliner.html

[42] Warren, A.S. Developments and Challenges for Aluminium-A Boeing Perspective/Proc. of ICAA-9. 2004.

[43] Caujolle, M. First Titanium 3D-Printed Part Installed Into Serial Production Aircraft. Newsroom 2017, September 13, 2017. Available from: http://www.airbus.com/ newsroom/press-releases/en/2017/09/first-titanium-3d-printed-part-installed-intoserialproduction-.html

[44] Wohlers A. Wohlers Report 2017, 3D Printing and Additive Manufacturing State of the Industry, Annual Worldwide Progress Report, Wohlers Associates: Fort Collins, CO, 2017.

[45] Mies, D.; Marsden, W.; Warde, S. Overview of additive manufacturing informatics:“a digital thread". Integrating Materials and Manufacturing Innovation. 2016, 5(1), pp. 114 142 .

[46] O'Brien, M. Existing standards as the framework to qualify additive manufacturing of metals. Big Sky, MT, USA, EEE Aerospace Conference. IEEE. 2018, pp. 1-10. 
[47] George, C. Standard for Additively Manufactured Spaceflight Hardware by LaserPowder Bed Fusion in Metals. Huntsville, AL, USA, NASA Marshall Space Flight Center. 2017.

[48] Babu, S.S.; Love, L.J.; Peter, W.H.; Dehoff, R. Workshop Report on Additive Manufacturing for Large-Scale Metal Components-Development and Deployment of Metal Big-AreaAdditive-Manufacturing (Large-Scale Metals AM) System (No. ORNL/TM-2016/202). Oak Ridge National Lab.(ORNL), Oak Ridge, TN (United States). Manufacturing Demonstration Facility (MDF). 2016.

[49] Krueger, H. Standardization for Additive Manufacturing in Aerospace. Engineering. 2017, $3(5)$, pp. 585.

[50] Singamneni, S.; Yifan, L.V.; Hewitt, A.; Chalk, R.; Thomas, W. Additive Manufacturing for the Aircraft Industry: A Review. Journal of Aeronauics \& Aerospace Engineering. 2019, 8(1), pp. 1-13.

[51] Yusuf, S.M.; Cutler, S.; Gao, N. Review: The Impact of Metal Additive Manufacturing on the Aerospace Industry. Metals. 2019, 9(12), pp. 1286.

[52] Campbell Jr, F. Manufacturing Technology for Aerospace Structural Materials - Aerospace Engineering Materials Science. Flake C Campbell Jr ed. s.l.:Elsevier. 2011.

[53] Volen, J. 3D Printing the Friendly Skies: Additive Manufacturing \& the Future of the Aerospace Supply Chain. 2018. [Online]. [9 March 2020]. Available from: https://www. Manu facturingtomorrow. com/article/2018/10/3d-printing-the-friendly-skies-additivemanufacturing-the-future-of-the-aerospace-supply-chain/12337/

[54] Standard: Space Systems. Structures, Structural Components, and Structural Assemblies (AIAA S-110-2005). Reston, VA, USA: American Institute of Aeronautics and Astronautics. 2005.

[55] Samuel, M.P.; Mishra, A.K.; Mishra, R.K. Additive Manufacturing of Ti-6Al-4V Aero Engine Parts: Qualification for Reliability. Journal of Failure Analysis and Prevention. 2018, 18(1), pp. 136-144.

[56] DebRoy, T.; Wei, H.L.; Zuback, J.S.; Mukherjee, T.; Elmer, J.W.; Milewski, J.O.; Beese, A.M.; Deid, A.W.; De, A.; Zhang, W. Additive manufacturing of metallic components process, structure and properties. Progress in Materials Science. 2018, 92, pp. 112-224.

[57] Williams, J.C.; Starke Jr, E.A. Progress in structural materials for aerospace systems. Acta Materialia. 2003, 51(19), pp. 5775-5799.

[58] Metals Handbook. Metals Handbook: Properties and Selection: Nonferrous Alloys and Special Purpose Materials. 10th ed. Materials Park, Ohio: ASM International. 1998)

[59] Starke Jr, E.A.; Staley, J.T. Application of modern aluminium alloys to aircraft. In: Fundamentals of aluminium metallurgy. Charlottesville: Woodhead Publishing. 2011, pp. 747-783.

[60] Necşulescu, D.A. The effects of corrosion on the mechanical properties of aluminium alloy 7075-T6. Scientific Bulletin-University Politehnica of Bucharest. 2011, 73(1), pp. 223-229.

[61] Oskouei, R.H.; Ibrahim, R.N. An investigation on the fatigue behaviour of Al 7075-T6 coated with titanium nitride using physical vapour deposition process. Materials \& Design. 2012, 39, pp. 294-302. 